\section{PROBLEMS WITH THE \\ "PROBLEMS" WITH \\ PSYCHOPHYSICAL CAUSATION}

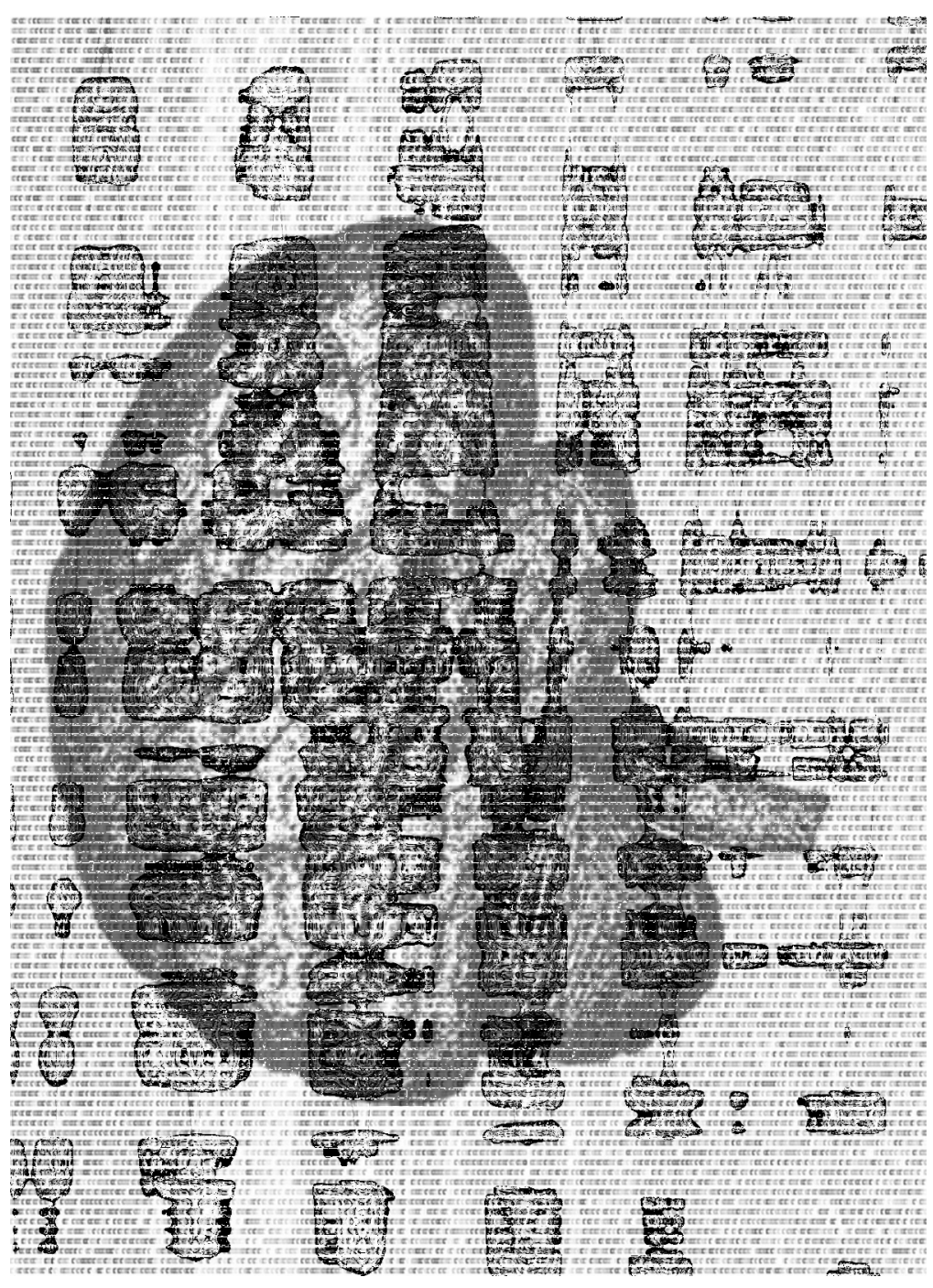

NOAH McKAY

\section{ABSTRACT}

In this essay, I defend a mind-body dualism, according to which human minds are immaterial substances that exercise non-redundant causal powers over bodies, against the notorious problem of psychophysical causation. I explicate and reply to three formulations of the problem: (i) the claim that, on dualism, psychophysical causation is inconsistent with physical causal closure, (ii) the claim that psychophysical causation on the dualist view is intolerably mysterious, and (iii) Jaegwon Kim's claim that dualism fails to account for causal pairings. Ultimately, I conclude that these objections fail and that dualist interactionism is no more problematic or mysterious than physical causation.

\section{INTRODUCTION: REVIVING DESCARTES'S DEAD HORSE}

In 1643, René Descartes, that venerated defender of the immaterial soul, received a letter from Princess Elisabeth of Bohemia, demanding that he explain "how the human soul can determine the movement of the animal spirits in the body so as to perform voluntary actsbeing as it is merely a conscious substance." ${ }^{1}$ This question, and others like it, have proven notoriously problematic for proponents of dualist interactionism. Psychophysical causation, causation of physical events by mental events, within a substance-dualist framework is widely thought to be inexplicable, mysterious, and inconsistent with a properly scientific view of the world, and this is taken to be a seriousindeed, a lethal—defect in the Cartesian account. In Jaegwon Kim's words, Cartesianism "founders on the rock of mental causation." In this essay, I will respond to various formulations of the problem of psychophysical causation from a dualist perspective. The dualism I represent is a broadly Cartesian substance-dualist interactionism (hereafter simply "dualism") according to which (i) human minds are immaterial, non-spatial, non-composite substances, (ii) mental properties and events are irreducibly mental — that is, they are not identical with, nor are they in any way reducible to, physical properties or events - and (iii) that some physical events are caused by mental, rather than physical, events (and vice-versa) — in sum, the archaic and very unfashionable position that the human person is, in Gilbert Ryle's deliberately abusive terminology, a "Ghost in [a] Machine." ${ }^{3}$ I do not

David Robb and John Heil, "Mental Causation," The Stanford

Encyclopedia of Philosophy, last modified October 10, 2018, https://plato. stanford.edu/entries/mental-causation/

2 Jaegwon Kim, "The Nonreductivist's Troubles with Mental Causation," in Supervenience and Mind: Selected Philosophical Essays (Cambridge: Cambridge University Press, 1993), 339.

3 Gillbert Ryle, The Concept of Mind (London: Hutchinson and Co., 1949), 16. 
pretend that psychophysical causation is the only problem with which dualism so characterized must grapple, nor do I intend to offer positive argumentation for dualism in this essay. I wish simply to remove what is probably the most serious and definitely the historically predominant obstacle to those considering dualism.

\section{THREE FORMULATIONS OF THE PROBLEM}

In this section, I will present explanations of and responses to three different versions of the problem of psychophysical causation: (i) the claim that, on dualism, psychophysical causation is inconsistent with physical causal closure (the "Closure Problem"); (ii) the claim that psychophysical causation on the dualist view is intolerably mysterious (the "Mystery Problem"); and (iii) Jaegwon Kim's contention that dualism fails to account for causal pairings (the "Pairing Problem.")

\section{A. THE CLOSURE PROBLEM}

First, many philosophers find dualism problematic in that it conflicts with the principle of the causal closure of the physical world. This principle is formulated by Jaegwon Kim:

The causal closure of the physical domain: If a physical event has a cause at $t$, then it has a physical cause at $t .{ }^{4}$

Causal closure boils down to the claim that any physical event can be explained solely in terms of other physical events. If this is true, it poses a problem for the dualist, for if some physical event, E, has a sufficient mental cause, $\mathrm{M}$, at some time, $t$ (which is indeed often true if dualism is true,) then $\mathrm{E}$ also has a sufficient physical cause, $\mathrm{P}$, at $t$. However, this means that $\mathrm{E}$ has more than one sufficient cause; that is, $\mathrm{E}$ is causally overdetermined. If we reject the possibility of genuine causal overdetermination - as nearly all philosophers of mind do as two events cannot both be the cause of something, since that would be redundantthis means that only one of either $\mathrm{P}$ or $\mathrm{M}$ caused $\mathrm{E}$. Because causal closure dictates that $\mathrm{E}$ must have a physical cause, $\mathrm{P}$ must win out over $M$. This means that $M$ is not causally efficacious in bringing about $E$; indeed, if causal closure is true (and causal overdetermination is rejected), no mental event ever causes any physical event to occur.

The heart of the problem here is obvious: the causal closure principle constitutes a flat denial of the dualist's thesis that non-

\section{This description should be taken to exclude the "non-reductive" materialist's} account of mental properties and events.

Jaegwon Kim, Physicalism, or Something Near Enough (Princeton:

Princeton University Press, 2005), 15. redundant, two-way causation occurs between the physical and mental domains. Causal closure is generally taken as an a priori premise in physicalist literature, and if it is so taken in the above argument, then the Closure Problem is question-begging: it presupposes the falsity of dualism from step one.

Can the anti-dualist present some argument for causal closure? Although such arguments are seldom offered, they do exist and are typically built upon empirical considerations. ${ }^{5}$ Andrew Melnyk, for instance, offers an enumerative-inductive argument for causal closure from the prior success of science in uncovering purely physical causes for previously unexplained phenomena. ${ }^{6}$ If science hasn't met with immaterial causes in past cases, it probably will not meet with them in future cases - or so the argument goes. This case for causal closure seems to me to be very weak; the fact that science has, so far, uncovered purely physical explanations for an impressive number of physical phenomena does not mean that it will uncover such explanations for all physical phenomena. Such extrapolation-with-abandon on the part of the physicalist seems to me to be entirely unjustified and indeed nearly as question-begging as the bare assertion of causal closure. This is especially so since the philosophical literature abounds with positive arguments for dualism; dualists have offered warrant for belief in irreducibly mental events that causally influence the physical world and so have offered warrant for believing that future scientific research will not uncover exhaustive, purely physical causal explanations for all physical events. John Foster argues that, given the relative meagerness of scientists' understanding of brain function, and given pre-scientific considerations offered in support of dualism, the sort of evidence that Melnyk appeals to "simply does not support the conclusion that the brain functions in a way which could be wholly accounted for (even from a God's-eye view) on the basis of its physical character and physical laws."7

Furthermore, I think we ought to be skeptical of claims made by the likes of Melnyk that science is marching forward in inexorable progress against the immaterial. Many reputable theistic - and even non-theistic - philosophers and scientists in the last few decades have drawn attention to phenomena in cosmology, microbiology, and genetics which appear to defy naturalistic explanation and which seem to accord better with what Richard Swinburne terms personal

5 Justin Tiehen, "Explaining Causal Closure," Philosophical Studies : An International Journal for Philosophy in the Analytic Tradition 172, no. 9 (2015): 2418, doi:10.1007/s11098-014-0418-5.

6 Andrew Melnyk, A Physicalist Manifesto; Thoroughly Modern Materialism (Cambridge: Cambridge University Press, 2003), 289-90.

7 John Foster, The Immaterial Self: A Defence of the Cartesian Dualist Conception of the Mind (London: Routledge, 200), 105. 
explanation: the fine-tuning of physical constants and quantities in the universe for the existence of conscious, interactive life, the information content of DNA sequences, and the enormous probabilistic difficulties facing naturalistic accounts of the origin of life, to name a few. ${ }^{8}$

Whatever our estimation of theism, and whether or not we think that these phenomena are ultimately naturally explicable, we ought at least to admit that science is having a bit of a hard time subsuming these sorts of phenomena under purely physical causal explanations. Not only does Melnyk's enumerative-inductive inference to causal closure reach far beyond what his premise justifies, but this premise itself is open to serious question. The Closure Problem, therefore, seems to me to be hopelessly weak at best and question-begging at worst.

It is worth noting at this point that some philosophers have formulated the problem of psychophysical causation in terms of energy conservation, arguing that dualistic psychophysical causation would "create" new energy in the human brain, thereby violating fundamental physical laws. ${ }^{9}$ This formulation of the problem is, I submit, little more than a narrowing of the Closure Problem, since conservation laws apply only to causally closed systems, and so any anti-dualist appealing to conservation laws must beg the question by presupposing causal closure. This is certainly not the only defect in these arguments (Robin Collins has discussed others), but it is decisive in my view. ${ }^{10}$

\section{B. THE MYSTERY PROBLEM}

Second, the problem of psychophysical causation might be put as the objection that psychophysical causation on dualism is somehow mysterious to an intolerable degree; this is probably the most prevalent version of the problem in the philosophical literature. I will address three ways in which the "Mystery Problem" might be formulated: first, it might be formulated as the objection that dualists are unable to provide an adequate mechanism for psychophysical causation; second, it

8 Richard Swinburne, The Existence of God (Oxford: Clarendon Press,

2004), 35-38. See Alvin Plantinga, Where the Conflict Really Lies: Science,

Religion, and Naturalism (Oxford: Oxford University Press, 2011); Antony

Flew and Roy Abraham Varghese, There is a God: How the World's Most Notorious Atheist Changed His Mind (New York: HarperOne, 2007); and Stephen Meyer, Signature in the Cell: DNA and the Evidence for Intelligent Design (New York: HarperOne, 2009) for interesting discussions of these problems by credentialed philosophers.

9 Howard Robinson, "Dualism," The Stanford Encyclopedia of Philosophy, last modified February 29, 2016, https://plato.stanford.edu/entries/dualism/.

10 See Robbin Collins, "Modern Physics and the Energy-Conservation

Objection to Mind-Body Dualism," American Philosophical Quarterly 45, no. 1 (Jan. 2008): 31-42. Collins argues that energy conservation laws are not universally generalizable, since they do not apply in General Relativity theory, and that quantum mechanics sets a precedent for causal interaction without energy transfer. might be formulated as the objection that dualism posits unintelligible causal relations between radically different kinds of substances; third, it might be put as the objection that dualist psychophysical causation is exceedingly strange and wholly unfamiliar to us, and should therefore be eliminated in favor of more familiar (i.e. physical) causes.

The first instance of the Mystery Problem objects that no mechanism for dualist psychophysical causation is available - that is, we cannot think of how mental events might cause physical events. This objection fails, for no matter what account of causation the antidualist espouses, he must posit a great number of instances of causation for which no mechanism can be provided, for which no how can be given. For he must inevitably admit immediate causation at some level. Consider a commonplace example of physical causation: the throwing of a baseball causing the shattering of a window. It will be helpful, both for clarity and for precision, to represent this event by the following finite series:

$$
\mathrm{P}_{1} \rightarrow \mathrm{P}_{2} \rightarrow \mathrm{P}_{3} \ldots \mathrm{P}_{\mathrm{n}-1} \rightarrow \mathrm{P}_{\mathrm{n}}
$$

In this series, each term stands for a physical event, and “ $\rightarrow$ " stands for "causes." The first term, $\mathrm{P}_{1}$, stands for the throwing of the baseball, and the last term, $\mathrm{P}_{\mathrm{n}}$, stands for the shattering of the window. The terms in between stand for all of the events in the causal chain between $\mathrm{P}_{1}$ and $\mathrm{P}_{\mathrm{n}}$ - for instance, the flying of the baseball through the air, the contact of the baseball with the glass, etc. ${ }^{11}$ Presumably, providing a mechanism by which $\mathrm{P}_{1}$ causes $\mathrm{P}_{\mathrm{n}}$ consists of identifying and describing the intervening events between $\mathrm{P}_{1}$ and $\mathrm{P}_{n}$ in the above series. In other words, to provide a mechanism is to describe precisely what happened between $\mathrm{P}_{1}$ and $\mathrm{P}_{n}$. (Allegedly, this is necessary to give an explanation for how $\mathrm{P}_{1}$ caused $\mathrm{P}_{\mathrm{n}}$.) I do not know how else one might construe "mechanism" in this objection; it cannot refer to a literal mechanical, chemical, or micro-physical apparatus since many instances of physical causation — such as a baseball's shattering of a window-do not involve any mediating apparatus. Furthermore, by describing the intervening events between $\mathrm{P}_{1}$ and $\mathrm{P}_{\mathrm{n}}$, we would describe the operation of any apparatus involved.

Now, if the above series is finite, then the causal relation (represented by “ $\rightarrow$ ") between any one of the events in the series and the event directly following it must be immediate; that is, there must be no mechanism by which one event causes the next, since there are no intervening events between them. Nothing happens between, say, $\mathrm{P}_{1}$ and $\mathrm{P}_{2}$. There is no how. So the principle behind this version of the Mystery Problem applies equally to purely physical causation-indeed,

11 These events can be taken as physical events of any sort, as complex or as basic, as enduring or as fleeting, as you like; my argument works at any level of reduction. 
to causation of any kind. In Foster's words, "presumably the notion of direct causation is not as such problematic: indeed, whenever causation operates, there has to be some direct causation." 12 The dualist is free to say that, when a mental event causes a physical event, the last mental event in the causal series causes the first physical event in the series immediately, without any intervening causes; only a " $\rightarrow$ " separates them. And, no charge can be brought against them that cannot also be brought against one who claims that baseballs shatter windows.

But what if the number of events in the causal series is infinite such that, for any two events in the series, there is always at least one intervening event between them? While this proposal might eliminate immediate causation, it ultimately renders provision of a mechanism for any instance of causation impossible, because it is impossible to enumerate and describe each of the infinitely many intervening events between two events in the series. We might try to solve this by subsuming every intervening event between $\mathrm{P}_{1}$ and $\mathrm{P}_{n}$ under a single term, $\mathrm{P}_{\mathrm{S}}$, so that all of the infinitely many events between them are summarized as "the baseball flew through the air and collided with the window." However, the same problem arises here as with a finite series: no mechanism has been provided by which $\mathrm{P}_{1}$ caused $\mathrm{P}_{\mathrm{S}}$ or by which $\mathrm{P}_{\mathrm{S}}$ caused $\mathrm{P}_{\mathrm{n}}$. Thus, the positing of infinite causal series does nothing to strengthen the objection.

Second, the Mystery Problem might be taken as the charge that dualist psychophysical causation is implausible in that it posits causal relations between two fundamentally different kinds of things, things which, in Howard Robinson's word, "lack that communality necessary for interaction." 13 The assumption here is that the mind, in order to interact causally with physical objects, must share a certain set of characteristics with those objects, or that it must belong to the same ontological "realm." In response, the dualist might ask: why? Why think that causation could not occur between two things with radically different characteristics or belonging to different ontological categories? The anti-dualist might point out that familiar cases of causal interaction between physical objects would be impossible unless all of the objects in question shared certain properties, such as spatial location and extension. And since the dualist's immaterial ego does not share these properties, this excludes it from causal interactions with physical things. However, it is hard to see how this follows: after all, the dualist does not assert that psychophysical causation is anything like physical-to-physical causation. If the anti-dualist's claim is that immaterial minds cannot stand in the same sorts of causal relations in which physical things stand to one another (or in which mental events stand to one another), his claim is not very interesting; the dualist does not postulate that the causal relations between minds and bodies are of this sort. Furthermore, I do not see how an argument could be made that there cannot be any other sorts of causal relations; there is just no good reason to accept the claim that fundamentally different things cannot interact. In Kim's estimation, this version of the Mystery Problem "is incomplete and unsatisfying. As it stands, it is not much of an argument; rather, it only expresses a vague, inchoate dissatisfaction." 14 As it turns out, this objection begs the question against the dualist's thesis that causal relations do, in fact, bridge ontological realms.

Third, the Mystery Problem might be put as the objection that psychophysical causation is exceedingly strange or unfamiliar to us relative to physical-to-physical causation and so ought to be jettisoned in favor of the latter. It might be argued that physical causation is the most credible explanatory resource we have, since we are constantly surrounded by it; we are much better acquainted with it than with any ghostly causal powers that the dualist might posit. So, we ought to eliminate such unfamiliar causes in favor of purely physical ones whenever possible - which turns out to be always. The Mystery Problem in this form is question-begging in two ways: first, it begs the question against the dualist's claim that psychophysical causation is explanatorily indispensable; second, if dualism is true, every one of us is intimately acquainted with psychophysical causation, since we engage in it moment-by-moment. Indeed, if dualism is true, then we are arguably more familiar with psychophysical causation than we are with physical causation; there is nothing unfamiliar or mysterious about it. The anti-dualist could only deny this by presupposing dualism to be false.

The Mystery Problem is bankrupt. In fact, it is a pseudo-problem; that is, the dualist need not worry about solving it, because there is not even a problem to solve. Mental-to-physical causation on dualism is no more mysterious, implausible, or inexplicable than physical-to-physical causation.

\section{THE PAIRING PROBLEM}

In his book, Physicalism, or Something Near Enough, Jaegwon Kim offers a version of the problem of psychophysical causation that he calls the "Pairing Problem:"

Let us begin with a simple example of physical causation: two guns, A and $B$, are simultaneously fired, and this results in the simultaneous death of

two persons, Adam and Bob. What makes it the case that the firing of $A$

caused Adam's death and the firing of B caused Bob's death, and not the

14 Kim, Physicalism, 74 
other way around? What are the principles that underlie the correct and incorrect pairings of cause and effect in a situation like this? ${ }^{15}$

Kim's answer: A stood in certain spatial relations to Adam at the moment it was fired that B did not, such that the bullet fired from A rather than from B killed Adam, and likewise for B and Bob. Kim goes on to argue that, since souls are not located in space, the dualist cannot give a similar explanation of why certain souls cause physical events in certain bodies, rather than others. After all, we can imagine a scenario in which two souls in qualitatively identical states cause qualitatively identical physical events in qualitatively identical bodies. Which soul caused which event in which body? Since neither soul is in space, the dualist cannot appeal to spatial relations to answer this question. In order to account for the pairings, the dualist needs some relation, $\mathrm{R}$, analogous to a spatial relation, in which each soul stands to only one body. According to Kim, they do not have one. ${ }^{16}$ As it turns out, Kim intends this as a more rigorous formulation of the third version of the Mystery Problem above; since souls are dissimilar to physical things in that they are non-spatial, they cannot interact with them.

The pairing problem is open to multiple objections (some of which Foster has enumerated), but I will focus on what I take to the most lethal: I contend that the dualist may properly take $\mathrm{R}$ to be a basic relation, that is, a relation that cannot be analyzed or explained in terms of other relations, and so Kim's demand for a description or an analysis of such a relation from the dualist is unreasonable. ${ }^{17}$ When the physicalist asks, "How is it that certain bodies are united with certain minds and not with others?" the dualist may justifiably answer, "They just are." They need go no further than saying that one soul in the above example does, in fact, stand in some relation $\mathrm{R}$ to one body in which the other soul does not stand to that body that accounts for the relevant pairing.

Kim objects to this answer: "For it concedes that the notion of 'union' of a mind and a body, and hence the notion of a person, is unintelligible. For what is it for a wholly immaterial thing to be 'united' or 'joined' with a material body with a specific location in space? The word 'united' merely gives a name to a mystery rather than clarifying it." 18 This is false; to admit that $\mathrm{R}$ is unanalyzable is not to admit that it is unintelligible. Even if the dualist cannot analyze $\mathrm{R}$ in terms of other more basic relations, this is unproblematic, for neither can this

15 Kim, Physicalism, 78-79.

16 Kim, Physicalism, 79-80.

17 See Foster, The Immaterial Self, 87-91. Foster contends that it is

conceivable that indeterministic physical laws might result in a similar pairing problem for physical causation, and so the physicalist faces the same difficulty.

8 Kim, Physicalism, 78 be done, ultimately, with the spatial relations that determine physical causal pairings. For instance, if we start with spatial contiguity as our candidate for this relation, we can analyze it in terms of distance and direction, and perhaps these can be analyzed in terms of more basic spatial relations. But if contiguity is to be defined non-circularly, Kim's analysis must eventually terminate in some basic spatial relation $\mathrm{R} \star$ that is unanalyzable in terms of other relations, just as $\mathrm{R}$ for the dualist is unanalyzable. ${ }^{19}$ To put it another way, the dualist might ask, "How is it that bullet B stands in the relation of spatial contiguity to Bob, but A does not?" to which Kim might answer, "Because bullet B stands in such-and-such more basic spatial relations to Bob, which bullet A does not." However, Kim cannot keep this up forever. The dualist can ask the same question about these more basic relations, and eventually Kim will have to answer, "It just does."

This does not mean, of course, that $\mathrm{R}^{\star}$, whatever it is, is unintelligible: Kim may clarify $\mathrm{R}^{\star}$ by pointing to examples in the physical world where $\mathrm{R}^{\star}$ is exemplified, such as the rifle example. In the same way, the dualist may point to examples in which $\mathrm{R}$ is exemplified: each of us is one such example. Further, he can make intelligible claims about R; namely, that it is the relation in which one's mind stands to one's body such that the former is able to cause changes in the latter and vice-versa. A similar claim could be made about $\mathrm{R} \star$. So, Kim is in the same boat as the dualist: physical causal pairings are ultimately determined by unanalyzable spatial relations that can only be clarified by example. The pairing problem, then, turns out to be another pseudo-problem, as it ascribes unintelligibility to unanalyzable relations, when in fact such relations can be perfectly intelligible and must be countenanced by any account of causation, including Kim's.

\section{CONCLUSION}

The above formulations of the problem of psychophysical causation are entirely unsuccessful as refutations of dualism. Those of them that are not question-begging can be applied with equal force against any account of physical causation. Cartesianism has not foundered on the rocks just yet; if it is to run aground, it must be elsewhere.

9 It is technically untrue that such an analysis must terminate in an unanalyzable spatial relation: $R^{\star}$ might be analyzed in terms of causal relations. That is, an object $A$ might be said to stand in $R^{\star}$ to an object $B$ iff $A$ stands in such-and-such causal relations to $B$. But if $R^{*}$ is analyzed in terms of causal relations, it cannot serve to determine causal pairings, since it presupposes them. 
ABOUT THE AUTHOR:

Noah McKay is a sophomore at

Covenant College in Lookout

Mountain, Georgia, majoring

in philosophy and minoring in

theology. His philosophic interests

include (but are certainly not limited

to) analytic philosophy of religion,

philosophy of mind, and mereology.

His greatest aspiration is to teach

and write philosophy professionally. 